Jurnal Ilmu Ilmu Agribisnis: Journal of Agribusiness Science, 9(3), Agustus 2021

\title{
ANALISIS PENGENDALIAN PERSEDIAAN PAKAN TERNAK SAPI PADA PT INDO PRIMA BEEF DI KABUPATEN LAMPUNG TENGAH
}

\author{
(Cattle Feed Inventory Control Analysis of PT Indo Prima Beef, Center Lampung Regency)
}

Yustika, Adia Nugraha, Rabiatul Adawiyah

Jurusan Agribisnis, Fakultas Pertanian, Universitas Lampung, J1. Prof. Dr. Soemantri Brojonegoro No. 1 Bandar Lampung 35145, e-mail: adia.nugraha@fp.unila.ac.id

\begin{abstract}
The purposes of this study are to analyze cost-efficient control of feed raw material inventory, anticipate shortages of supply, determine the correct time frame for reordering raw materials at the feedlot company PT Indo Prima Beef using the Economic Order Quantity (EOQ) mathematical model and determine the inventory value of raw materials with the First In First Out (FIFO) assessment model. Data collection was carried out in March-May 2020 using a case study method. The data used were primary data collected using questionnaires and secondary data from literature studies. The results showed that the inventory cost applied by PT Indo Prima Beef was different from the calculation of the EOQ model. According to EOQ analysis, the largest amount of safety stock is corn sugarcane as much as $139,725.95 \mathrm{~kg}$, and the lowest amount is salt around $870.63 \mathrm{~kg}$. The reorder point for PT Indo Prima Beef with the largest amount was dry onggok as much as $139,926 \mathrm{~kg}$, while the lowest amount was $724.87 \mathrm{~kg}$ of salt. PT Indo Prima Beef uses a perpetual recording system with the First In First Out (FIFO) inventory valuation method with a total raw material inventory value of IDR2,129,68,820 in one year.
\end{abstract}

Key words: EOQ,FIFO, inventory, supplies

\section{PENDAHULUAN}

Salah satu provinsi di Indonesia dengan potensi besar dalam pengembangan ternak sapi potong sebagai upaya pemantapan ketahanan pangan nasional adalah Provinsi Lampung, terutama ternak sapi potongBerdasarkan data Badan Pusat Statistik (BPS) Provinsi Lampung tahun 2018, disimpulkan bahwa populasi ternak sapi di Provinsi Lampung terus meningkat mulai tahun 2016 sebanyak 665.712 ekor menjadi 826.980 ekor pada 2018. KabupatenLampung Tengah menjadi sentra ternak sapi potong karena banyak terdapat perusahaan penggemukan sapi salah satunya adalah PT Indo Prima Beef yang didirikan pada tahun 2014 di Kecamatan Terbanggi Besar dengan jumlah ternak sapi kurang lebih tiga ribu ekor saat ini.

Produktivitas ternak sapi sebagian besar dipengaruhi oleh pakan ternak. Pakan dari sudut nutrisi merupakan salah satu unsur yang sangat penting untuk menunjang kebutuhan hidup pokok, pertumbuhan, produksi dan atau reproduksi ternak. Jumlah populasi ternak yang besar pada perusahaan tersebut, membutuhkan jumlah pakanyang besar pula. Bahan baku pakan ternak yang diperlukan perusahaan tidak selalu ada setiap waktu, sehingga perusahaan memerlukan persediaan bahan baku. Jika tidak ada persediaan bahan baku maka perusahaan akan dihadapkan pada risiko yaitu tidak dapat berproduksi untuk memenuhi kebutuhan yang diinginkan oleh konsumen, sehingga perusahaan dapat mengalami kerugian besar. Hal ini karena ketidakpastian tersedianya bahan baku yang diinginkan perusahaan. Pengendalian persediaan bahan baku menjadi bagian yang penting karena jumlah persediaan bahan baku akan menentukan atau memengaruhi kelancaran proses produksi.

Salah satu upaya perusahaan untuk meminimalkan biaya persediaan adalah dengan menerapkan manajemen pengendalian persediaan yang tepat.Ada beberapa model dalam manajemen pengendalian persediaan antara lain model deterministik Economic Order Quantity (EOQ). Model ini dapat digunakan oleh perusahaan baik untuk barang-barang yang dibeli maupun yang diproduksi sendiri (Handoko1984). Melalui model ini juga perusahaan dapat menghitung biaya persediaan dan persediaan pengaman.Berdasarkan uraian sebelumnya maka tujuan dari penelitian ini adalah menganalisis pengendalian dan penilaian 
persediaan bahan baku pakan pada PT Indo Prima Beef.

\section{METODE PENELITIAN}

Penelitian ini menggunakan metode studi kasus padaPT Indo Prima Beef yang merupakan perusahaan penggemukan sapi yang berada di Kabupaten Lampung Tengah. Pemilihan lokasi penelitian dilakukan secara sengaja (purposive) dengan pertimbangan bahwa perusahaan tersebut merupakan salah satu perusahaan penggemukan sapi yang aktif berproduksi dengan jumlah ternak sekitar tiga ribu ekor dan dengan persediaan pakan yang cukup banyak sejak tahun 2014 hingga sekarang (6 tahun) di Lampung Tengah.Data yang digunakan dalam penelitian ini terdiri dari data primer dan sekunder.

Data primer merupakan data yang diperoleh melalui wawancara dengan karyawan bagian persediaan pakan dan bagian gudang PT Indo Prima Beef dengan menggunakan kuesioner,dan pengamatan langsung di lapangan, sedangkan data sekunder merupakan data yang diperoleh berdasarkan literatur-literatur yang berhubungan dengan penelitian dan data dari instansi-instansi terkait seperti Badan Pusat Statistik dan data stok dari PT Indo Prima Beef. Responden dalam penelitian ini berjumlah 4 orang yaitu karyawan yaitu satu orang karyawan bagian stockman, satu orang karyawan bagian humas, satu orang karyawan bagian gudang bahan pakan, serta general manager. Metode penelitian ini adalah studi kasus dengan metode analisis deskriptif kuantitatif.

Analisis Biaya dan Kuantitas Pembelian Persediaan dengan Perhitungan EOQ menurut Heizer dan Barry (2010), pemilihan metode penelitian ini sejalan dengan penelitian Pertiwi, Affandi, dan Kasymir (2015) yang menggunakan EOQ untuk menentukan kuantitas pembelian persediaan. EOQ dapat dihitung dengan rumus :

$\mathrm{EOQ}=\sqrt{ }(2 \mathrm{DS} / \mathrm{H})$

Keterangan :

$\mathrm{EOQ}=$ Economic Order Quantity

$\mathrm{S}=$ Biaya setiap kali pesan

$\mathrm{D}=$ Jumlah kebutuhan bahan baku dalam satu periode

$\mathrm{H}=$ Biaya penyimpanan dari persediaan rata-rata
Analisis Jumlah Persediaan Pengaman menggunakan rumus safety stock menurut Stevenson dan Chee (2014).

$\mathrm{SS}=\sqrt{ }\left(\left(\sum \mathrm{L}(\mathrm{SDd})+\sum \mathrm{D}(\mathrm{SDl})\right) / \mathrm{N}\right)$

Keterangan :

$\mathrm{SS}=$ Safety Stock

$\Sigma \mathrm{L}=$ Lead time rata-rata

$\sum \mathrm{D}=$ tingkat pemakaian bahan rata-rata $(\mathrm{kg})$

SDd = Standar deviasi pemakaian bahan baku

$\mathrm{SDl}=$ Standar deviasi lead time

Analisis Titik Pemesanan Kembali (Re-Order

Point) bahan dengan menggunakan rumus:

$\mathrm{ROP}=\mathrm{dxLT}+$ safetystock

Keterangan :

$\begin{array}{ll}\text { ROP } & =\text { Re-order Point } \\ \mathrm{d} & =\text { Tingkat permintaan (unit per } \\ & \text { hari atau per minggu) } \\ \text { LT } & =\begin{array}{l}\text { Waktu tunggu dalam hari atau } \\ \text { minggu }\end{array}\end{array}$

Safety Stock = Persediaan pengaman perusahaan (Stevenson danChee, 2014)

Analisis Penilaian Persediaan Bahan Baku Pakan dalam suatu periode dilakukan dengan menggunakan metode First In First Out (FIFO) dengan pertimbangan bahwa bahan baku pakan merupakan bahan baku yang bersifat bulky atau mudah rusak sehingga persediaan yang masuk pertama akan keluar pertama kali. Penilaian persediaan dilakukan agar perusahaan dapat mengetahui biaya dan laba perusahaan.

\section{HASIL DAN PEMBAHASAN}

\section{Keadaan Umum Perusahaan}

PT Indo Prima Beef adalah perusahaan penggemukan sapi yang berawal dari usaha keluarga, berdiri sejak tahun 1990-an dilahan seluas $32.000 \mathrm{~m}^{2}$. PT Indo Prima Beef didirikan oleh Bapak Drh. Nanang Purus yang merupakan lulusan dari Fakultas Kedokteran Hewan Universitas Gadjah Mada. Pada awalnya perusahaan ini berbentuk usaha peternakan sapi keluarga, lalu karena semakin berkembang peternakan berubah bentuk perusahaan menjadi Persekutuan Komanditrer (CV) dan pada awal tahun 2014 berubah menjadi Perseroan Terbatas (PT) hingga sekarang. 


\section{Deskripsi Objek Penelitian}

Bahan Baku Pakan yang digunakan meliputi tebon jagung, onggok kering, bungkil jagung (DDGS), Soy bean meal, molases, bungkil kopra, dan bungkil sawit.Bahan baku penolong atau bahan baku yang jumlah pemakaiannya sedikit antara lain dolomit, polar, urea, kapur, dan garam.PT Indo Prima Beef mendapatkan bahan baku pakan dari beberapa pemasok, semua pemasok bahan pakan masih berasal dari Provinsi Lampung. Perusahaan memilih pemasok yang berada di Provinsi Lampung agar waktu pengiriman bahan pakan tidak terlalu lama.

\section{Biaya Persediaan Bahan Baku Pakan}

Biaya persediaan bahan baku adalah total biaya yang dikeluarkan perusahaan yang meliputi biaya pemesanan dan biaya penyimpanan.Biaya pemesanan pada PT Indo Prima Beef berupa biaya pulsa karena pemesanan dilakukan melalui telepon dan tidak ada biaya admisitrasi serta biaya transportasi, berdasarkan keterangan pihak perusahaan biaya-biaya tersebut ditanggung oleh pemasok, sehingga perusahaan menerima bersih bahan baku yang dipesan dengan harga yang telah disepakati antara pihak perusahaan dan pemasok. Biaya pemesanan PT Indo Prima Beef berupa pulsa sebesar Rp2.000 per pesanan.

Biaya persediaan selanjutnya adalah biaya penyimpanan,berupa penyusutan persediaan.Biaya penyusutan persediaan bahan baku pada PT Indo Prima Beef sebesar 5 persen dari total biayapembelian bahan baku selama satu tahun. Penyusutan dihitung konstan oleh perusahaan sebagaimana bahan baku pakan mengalami penyusutan kadar air ketika disimpan. Biaya penyimpanan bahan baku selama satu tahun adalahRp98,46/Kg.

\section{Analisis Biaya Persediaan Bahan Baku PT Indo Prima Beef Tahun 2019}

Analisis biaya persediaan bahan baku yang diterapkan di PT Indo Prima Beef akan dibandingkan dengan analisis biaya persediaan dengan menggunakan model EOQ. Perbandingan frekuensi dan jumlah unit per pesanan antara model pengendalian PT Indo Prima Beef dengan model pengendalian EOQ dapat dilihat pada Tabel 1. Kebijakan frekuensi pemesanan PT Indo Prima Beef jumlahnya lebih sedikit dibandingkan dengan frekuensi yang dihitung dengan model EOQ, sehingga jumlah bahan baku yang dipesan lebih banyak dalam satu kali pesannya agar persediaan mencukupi dan proses produksi tetap berjalan.Hal ini dapat menyebabkan besarnya biaya persediaan.

Berdasarkan hasil analisis ini pengadaan bahan baku pada PT Indo Prima Beef lebih efektif dalam frekuensi pemesanan bahan baku dan jumlah bahan baku yang dipesan dibandingkan dengan model EOQ, hal ini sejalan dengan penelitian Wulandari, Widjaya, dan Suryani (2017)dan penelitian Setyanto (2019) yang menyebutkan bahwa model EOQ lebih efisien digunakan pada pengendalian pakan ternak sapi. Hasil perhitungan frekuensi dan jumlah pemesanan pada Tabel 1 akan relevan digunakan pada perusahaan berskala besar seperti PT Indo Prima Beef apabila perhitungan jumlah frekuensi dan jumlah unit pemesanan menyesuaikan dengan keadaan dan kemampuan pasar bahan baku pakan memenuhi permintaan.

Tabel 1. Perbandingan frekuensi dan jumlah unit pemesanan bahan baku 2019

\begin{tabular}{|c|c|c|c|c|c|c|}
\hline \multirow[b]{2}{*}{ Bahan pakan } & \multicolumn{2}{|c|}{ Frekuensi Pemesanan } & \multirow{2}{*}{$\begin{array}{l}\text { Perbedaan } \\
\text { Frekuensi } \\
(\%)\end{array}$} & \multicolumn{2}{|c|}{ Jumlah Unit Pesanan } & \multirow{2}{*}{$\begin{array}{l}\text { Perbedaan } \\
\text { jumlah unit } \\
\text { pesanan }(\%)\end{array}$} \\
\hline & $\begin{array}{l}\text { Perusahaan } \\
\text { (kali/tahun) }\end{array}$ & $\begin{array}{c}\text { EOQ } \\
\text { (kali/tahun) }\end{array}$ & & $\begin{array}{c}\text { Perusahaan } \\
\text { (kg/pesan) }\end{array}$ & $\begin{array}{c}\text { EOQ } \\
\text { (kg/pesan) }\end{array}$ & \\
\hline Tebon jagung & 351 & 365 & 4,00 & 18.665 & 17.481 & 6,34 \\
\hline Onggok kering & 291 & 365 & 25,42 & 16.748 & 11.856 & 29,20 \\
\hline Bungkil jagung & 24 & 365 & $1.420,83$ & 22.318 & 1.752 & 92,14 \\
\hline Soy bean meal & 58 & 365 & 529,31 & 14.635 & 2.105 & 85,61 \\
\hline Molasses & 69 & 365 & 428,98 & 20.835 & 3.248 & 84,40 \\
\hline Bungkil kopra & 50 & 365 & 630 & 24.996 & 3.084 & 87,65 \\
\hline Bungkil sawit & 59 & 365 & 666,1 & 17.881 & 1.898 & 89,38 \\
\hline Dolomit/kapur & 34 & 225 & 561,76 & 5.438 & 760 & 86,01 \\
\hline Pollard & 51 & 365 & 635,29 & 10.222 & 1.307 & 87,20 \\
\hline Urea & 10 & 208 & 1980 & 9.456 & 702 & 92,57 \\
\hline Garam & 24 & 97 & 304,16 & 1.136 & 330 & 70,93 \\
\hline
\end{tabular}


Tabel. 2 Asal bahan baku pakan

\begin{tabular}{llc}
\hline No & Asa lbahan baku & Jenis bahan baku \\
\hline 1. & Pemasok Lampung & $\begin{array}{c}\text { Tebon jagung } \\
\text { Dolomit/Kapur } \\
\text { Pollard } \\
\text { Garam }\end{array}$ \\
\hline 2. & $\begin{array}{l}\text { CV Harapan } \\
\text { (Lampung) }\end{array}$ & \begin{tabular}{c} 
Bungkil jagung \\
\hline 3.
\end{tabular} \\
& $\begin{array}{l}\text { CV Surya Kencana } \\
\text { (Lampung) }\end{array}$ & $\begin{array}{l}\text { Soy bean meal } \\
\text { Bungkil kopra } \\
\text { Bungkil sawit } \\
\text { Urea }\end{array}$ \\
\hline 4. & $\begin{array}{l}\text { PT Aman } \\
\text { (Lampung) }\end{array}$ & Molases \\
\hline
\end{tabular}

Perbedaan persentase yang besar ini terjadi karena pada keadaan aktual perusahaan, pasar bahan baku tidak bekerja sempurna, dimana bahan baku tidak tersedia setiap waktu, dan bahan baku tidak berasal hanya dari satu pemasok (spreadable) serta pemasok tidak hanya memenuhi permintaan satu perusahaan saja. Asal bahan baku dapat dilihat pada Tabel 2.

\section{Perbandingan Total Biaya Persediaan antara Model Perusahaan dengan Model EOQ}

Total biaya persediaan meliputi biaya penyimpanan dan biaya pemesanan, perhitungan biaya persediaan dapat dilihat pada Tabel 3. Total biaya persediaan berdasarkan perhitungan menurut teori, perbandingan total biaya antara model perusahaan dan model EOQ menunjukan bahwa PT Indo Prima Beef tahun 2019 dapat menghemat biaya persediaan tiap bahan baku yang tadinya
Rp97.941.618 menjadi Rp18.778.751dengan menggunakan model EOQ. Penghematan biaya tersebut sebesar Rp79.162.867,-.. atau 80,83 persen dari total biaya persediaan tahun 2019 dengan menggunakan model dari perusahaan. Perbandingan total biaya dapat dilihat pada Tabel 4.

Berdasarkan hasil analisis, biaya pengadaan bahan baku yang diterapkan perusahaan selama ini belum efisien, namun pada kenyataan perusahaan tetap berjalan hingga hampir 6 tahun lamanya tanpa menggunakan model pengendalian yang sesuai dengan teori, dalam hal ini antara metode perusahaan dan analisis berdasarkan teori penulis didapatkan perbedaan perhitungan yang mungkin disebabkan karena pada kenyataan nyata pasar tidak bekerja sempurna dan ada asumsi-asumsi yang tidak terpenuhi untuk model Economic Order Quantity, sehingga teori ini tidak relevan apabila digunakan pada perusahaan ini. Selain itu, perhitungan frekuensi pemesanan dan jumlah unit bahan baku pada teori tidak mempertimbangkan keadaan pasar bahan baku.

Hasil analisis pada penelitian ini tidak sejalan dengan penelitianWulandari, Widjaya,dan Suryani (2017) serta Apriyanti dan Wibowo (2017) yang menyatakan bahwa kebijakan pengendalian persediaan bahan baku dari perusahaan penggemukan sapi belum optimal dibandingkan dengan pengendalian persediaan bahan baku dengan model EOQ, dimana total biaya persediaan bahan baku dengan metode perusahaan lebih besar dibanding dengan model EOQ.

Tabel 3.Perhitungan biaya persediaan perusahaan dan biaya model EOQ 2019

\begin{tabular}{|c|c|c|c|c|c|c|c|c|}
\hline \multirow[b]{2}{*}{ Bahan pakan } & \multicolumn{2}{|c|}{ Frekuensi pemesanan } & \multicolumn{2}{|c|}{ Biaya pemesanan } & \multicolumn{2}{|c|}{$\begin{array}{l}\text { Jumlah rata-rata } \\
\text { persediaan per bulan }\end{array}$} & \multicolumn{2}{|c|}{ Biaya penyimpanan } \\
\hline & $\begin{array}{c}\text { Perusahaan } \\
\text { (kali/tahun) } \\
\text { (A) }\end{array}$ & $\begin{array}{c}\text { EOQ } \\
\text { (kali/tah } \\
\text { un) (B) }\end{array}$ & $\begin{array}{c}\text { Perusahaa } \\
\text { n (Ax Rp } \\
2000)\end{array}$ & $\begin{array}{l}\text { EOQ (B x } \\
\text { rp 2000) }\end{array}$ & $\begin{array}{l}\text { Perusaha } \\
\text { an }(\mathrm{kg}) \\
(\mathrm{C})\end{array}$ & $\begin{array}{l}\text { EOQ } \\
(\mathrm{kg}) \\
(\mathrm{D}) \\
\end{array}$ & $\begin{array}{c}\text { Perusahaan } \\
(\mathrm{C} \times \mathrm{Rp} \\
98,64)\end{array}$ & $\begin{array}{c}\text { EOQ } \\
\text { (D x Rp } \\
98,64) \\
\end{array}$ \\
\hline Tebon jagung & 351 & 365 & 702.000 & 730.000 & 111.991 & 27.896 & 11.026 .592 & 2.746 .689 \\
\hline Onggok kering & 291 & 365 & 582.000 & 730.000 & 100.486 & 22.976 & 9.893 .815 & 2.262 .198 \\
\hline Bungkil jagung & 24 & 365 & 48.000 & 730.000 & 133.909 & 8.809 & 13.184 .705 & 867.313 \\
\hline Soy bean meal & 58 & 365 & 116.000 & 730.000 & 87.810 & 9.677 & 8.645 .801 & 952.817 \\
\hline Molasses & 69 & 365 & 138.000 & 730.000 & 125.009 & 12.022 & 12.308 .366 & 1.183 .650 \\
\hline Bungkil kopra & 50 & 365 & 100.000 & 730.000 & 149.974 & 11.714 & 14.766 .460 & 1.153 .367 \\
\hline Bungkil sawit & 59 & 365 & 118.000 & 730.000 & 107.289 & 9.180 & 10.563 .647 & 903.857 \\
\hline Dolomit/kapur & 34 & 225 & 68.000 & 450.000 & 32.627 & 4.566 & 3.212 .450 & 449.586 \\
\hline Pollard & 51 & 365 & 102.000 & 730.000 & 61.329 & 7.610 & 6.038 .469 & 749.318 \\
\hline Urea & 10 & 208 & 20.000 & 416.000 & 56.736 & 4.220 & 5.586 .251 & 415.518 \\
\hline Garam & 24 & 97 & 48.000 & 194.000 & 6.816 & 1.975 & 672.026 & 194.438 \\
\hline Total & & & 2.044 .000 & 6.900 .000 & & & 95.897 .618 & 11.878 .751 \\
\hline
\end{tabular}


Tabel 4. Perbandingan total biaya persediaan bahan baku perusahaan dengan model EOQ 2019

\begin{tabular}{lccc}
\hline & Biaya perusahaan & Biaya model EOQ & Perbedaan total biaya \\
& (Rp/Tahun) & $(\mathrm{Rp} /$ Tahun $)$ & \\
\hline BiayaPenyimpanan & 95.897 .618 & 11.878 .751 & \\
Biayapemesanan & 2.044 .000 & 6.900 .000 & 80,83 \\
\hline Total biaya & 97.941 .618 & 18.778 .751 & \\
\hline
\end{tabular}

\section{Analisis Persediaan Pengaman (Safety Stock) pada PT Indo Prima Beef}

Persediaan pengaman (safety stock) adalah persediaan tambahan yang akan diadakan untuk melindungi atau menjaga kemungkinan terjadinya kekurangan bahan (stock out) Assauri (2008). Menghitung persediaan pengaman memerlukan data distribusi probabilitas dari lead time yang diperoleh dari hasil analisis data historis. Dari probabilitas lead time itu pula dapat diketahui mengenai probabilitas terjadinya stock out.

Persediaan pengaman bertujuan untuk mengantisipasi bila adanya penggunaan bahan baku yang lebih besar dari perkiraan awal produksi dan bila adanya peningkatan permintaan konsumen.Perhitungan persediaan pengaman PT Indo Prima Beef dengan model EOQ dapat dilihat pada Tabel 5

Asumsinya adalah bahwa distribusi probabilitas dari lead time merupakan disribusi normal, kemudian ditentukan service level yang menunjukkan probabilitas yang diharap bahwa perusahaan tidak akan mengalami stock-out selama lead time. Hasil perhitungan persediaan pengaman Persediaan pengaman pada dasarnya adalah persediaan yang disiapkan untuk mengantisipasi ketidakpastian yaitu variasi permintaan, waktu tunggu, dan tingkat pelayanan.

Tabel 5. Safety stock bahan pakan PT Indo Prima Beef 2019

\begin{tabular}{lccr}
\hline Bahan pakan & $\begin{array}{c}\text { Variasi } \\
\text { permintaan } \\
(\sigma \mathrm{T})\end{array}$ & $\begin{array}{c}\text { Servis } \\
\text { level }(\%)\end{array}$ & $\begin{array}{c}\text { Safety } \\
\text { stock }\end{array}$ \\
\hline Tebon Jagung & 25.382 & 95 & 41.627 \\
Onggok Kering & 33.604 & 95 & 55.112 \\
Bungkil Jagung & 15.271 & 95 & 25.045 \\
SBM & 11.746 & 85 & 12.169 \\
Molasses & 53.263 & 95 & 87.144 \\
Bungkil Kopra & 13.118 & 90 & 16.791 \\
Bungkil Sawit & 9.958 & 90 & 12.747 \\
Dolomit & 1.007 & 95 & 1.651 \\
Pollard & 2.437 & 95 & 3.997 \\
Urea & 2.039 & 95 & 3.344 \\
Garam & 275 & 95 & 451 \\
\hline
\end{tabular}

\section{Analisis Titik Pemesanan Kembali (Re-Order Point) pada PT Indo Prima Beef}

Menurut Stevenson dan Chee (2014), titik pemesanan kembali (re-order point) terjadi ketika kuantitas di penyimpanan jatuh hingga jumlah yang telah ditentukan sebelumnya.Pemesanan kembali bahan baku pakan harus dilakukan oleh PT Indo Prima Beef ketika masing-masing bahan baku mencapai atau mendekati nol, pemesanan kembali diperoleh dari perkalian antara lead time dan pemakaian ditambah dengan persediaan pengaman. Perhitungan titik pemesanan kembali pada PT Indo Prima Beef dapat dilihat pada Tabel 6.

Pada Tabel 6, didapatkan hasil titik pemesanan kembali dengan nilai tertinggi adalah bahan baku onggok kering. Hal ini disebabkan pemakaian ratarata bahan baku onggok kering besar, tetapipada tebon jagung titik pemesanan kembali tidak tinggi karena waktu tunggu rata-rata yang kecil walaupun pemakaian rata-rata besar. Manajemen perusahaan akan mempertimbangkan panjangnya waktu tunggu yang diperlukan di dalam pembelian bahan baku tersebut. Pembelian kembali yang dilaksanakan akan dapat mendatangkan bahan baku ke dalam gudang dalam waktu yang tepat, sehingga tidak akan terjadi kekurangan bahan baku karena keterlambatan kedatangan bahan baku atau

Tabel 6. Pemesanan kembali pada PT Indo Prima Beef 2019

\begin{tabular}{lcr}
\hline Bahan pakan & $\begin{array}{l}\text { Safety stock } \\
(\mathrm{kg}) \mathrm{z. \sigma T}\end{array}$ & \multicolumn{1}{c}{$\begin{array}{c}\text { Reorder point } \\
(\mathrm{kg})(\overline{\mathrm{L}} . \dot{\mathrm{D}})+\mathrm{SS}\end{array}$} \\
\hline Tebon jagung & $41.627,269$ & $59.519,000$ \\
Onggok kering & $55.112,000$ & $139.926,000$ \\
Bungkil jagung & $25.045,645$ & $53.049,000$ \\
Soy bean meal & $12.169,275$ & $28.015 ., 605$ \\
Molasses & $87.144,539$ & $108.470,883$ \\
Bungkil kopra & $16.791,247$ & $34.673,037$ \\
Bungkil sawit & $12.747,043$ & $24.994,429$ \\
Dolomit/kapur & $1.651,889$ & $3.093,989$ \\
Pollard & $3.997,271$ & $7.903,171$ \\
Urea & $3.344,584$ & $4.661,284$ \\
Garam & 451,278 & 724,878 \\
\hline
\end{tabular}


Tabel 7. Nilai persediaan bahan baku pakan PT Indo Prima Beef 2019

\begin{tabular}{lrrrr}
\hline \multicolumn{1}{c}{ Bahan baku } & Saldo awal (Rp) & $\begin{array}{c}\text { Nilai pembelian } \\
(\mathrm{Rp})\end{array}$ & $\begin{array}{c}\text { Nilai pemakaian } \\
(\mathrm{Rp})\end{array}$ & $\begin{array}{r}\text { Total nilai persediaan } \\
(\mathrm{Rp})\end{array}$ \\
\hline Tebon jagung & 7.542 .000 & 3.938 .976 .000 & 3.903 .629 .400 & 42.888 .600 \\
Onggok kering & 75.620 .000 & 9.500 .744 .800 & 8.299 .431 .800 & 1.276 .933 .000 \\
Bungkil jagung & 142.693 .750 & 2.798 .327 .500 & 2.856 .403 .750 & 84.751 .620 \\
Soy bean meal & 80.715 .600 & 5.276 .854 .800 & 5.141 .549 .700 & 261.261 .000 \\
Molasses & 107.500 .000 & 3.445 .550 .000 & 3.403 .142 .500 & 149.907 .500 \\
Bungkil kopra & 34.770 .000 & 3.057 .242 .500 & 2.882 .620 .000 & 209.395 .000 \\
Bungkil sawit & 14.518 .000 & 1.223 .716 .100 & 1.215 .204 .200 & 50.969 .400 \\
Dolomit/kapur & 25.560 .000 & 683.820 .000 & 692.200 .000 & 17.180 .000 \\
Pollard & 18.705 .000 & 1.656 .712 .600 & 2.015 .431 .500 & -59.593 .700 \\
Urea & 34.540 .100 & 906.061 .500 & 837.447 .700 & 92.103 .400 \\
Garam & 980.000 & 84.987 .500 & 82.085 .000 & 3.890 .000 \\
\hline
\end{tabular}

kelebihan bahan baku di gudang karena bahan baku yang dipesan datang lebih awal. Titik pemesanan kembali setiap perusahaan berbeda, titik pemesanan kembali dipengaruhi oleh besarnya persediaan pengaman yang ada di setiap perusahaan

\section{Penilaian Persediaan PT Indo Prima Beef}

Total nilai persediaan PT Indo Prima Beef merupakan data yang telah diolah berdasarkan informasi yang didapatkan dari kartu stok pakan. PT Indo Prima Beef menggunakan sistem perpetual dalam pencatatan persediaannya, maka pencatatan dilakukan setiap transaksi pembelian bahan baku maupun pemakaian (pengeluaran) bahan baku, dan untuk melakukan metode penilaian persediaan bahan baku pakan ternak menggunakan metode penilaian FIFO (Fist In First Out) dimana barang yang pertama masuk kedalam gudang penyimpanan atau gudang persediaan maka barang tersebut yang pertama keluar.

Perusahaan ini memiliki jenis persediaan yang cukup banyak dan merupakan produk yang mudah rusak (bulky), maka persediaan. yang awal masuk yaitu bahan baku yang pertama kali diperjual belikan atau digunakan. Penggunaan model FIFO (First In First Out) ini secara umum sudah sesuai dengan model penilaian dari Pernyataan Standar Akuntansi Keuangan (PSAK) No. 14 tahun 2012 yang diterbitkan Ikatan Akuntansi Indonesia (IAI), penelitian ini lebih terfokus pada mengetahui metode pencatatan dan penilaian yang digunakan perusahaan.

Penelitian ini berbeda dengan penelitian Zubaidah dan Rizki (2015) tentang penilaian persediaan pada
PT Mitra Tani Sari Panyambungan Medan menggunakan metode FIFO (First In First Out) yang bergerak dalam bidang pendistribusian barang dagang pertanian dan pakan tenak sehingga barang dagangan perusahaan ini memiliki masa kadaluarsa tertentu. Ringkasan perhitungan tiap bahan baku dapat dilihat pada Tabel 7 .

\section{KESIMPULAN}

Penerapan metode EOQ akan menghemat biaya persediaan bahan baku sebesar 80,83 persen. Pengendalian persediaan bahan baku pakan PT Indo Prima Beef dapat menggunakan model EOQ. Pengendalian dengan menggunakan metode two bin tidak efisien dalam biaya persediaan. Persediaan pengaman dan titik pemesanan kembali dapat dihitung dengan menggunakan model EOQ. Penilaian persediaan PT Indo Prima Beef sudah tepat dengan menggunakan metode penilaian FIFO (First In First Out) pada bahan baku pakan dengan nilai seluruh persediaan bahan baku Rp2.129.685.820 dalam satu tahun.

\section{DAFTAR PUSTAKA}

Apriyanti E dan Lestari L. 2017. Analisis pengendalian persediaan bahan baku melalui penerapan economic order quantity (eoq) pada PT Andini Megah Sejahtera cabang Bogor. Balance Vocation Accounting Journal, 1(2): 38.http://jurnal.umt.ac.id/index.php/bvaj/articl e/view/475/335.[11 Juli 2020].

Assauri S. 2008. Manajemen Produksi dan Operasi. Universitas Indonesia. Jakarta.

BPS [Badan Pusat Statistik] Provinsi Lampung. 2018. Populasi Ternak (Sapi) Menurut Kabupaten/Kota di Provinsi Lampung 2018. 
Jurnal Ilmu Ilmu Agribisnis: Journal of Agribusiness Science, 9(3), Agustus 2021

BPS Provinsi Lampung. Bandar Lampung [26 Oktober 2019].

Handoko TH. 1984. Dasar-dasar Manajemen Produksi dan Operasi. BPFE. Yogyakarta. 2014. Dasar-dasar Manajemen Produksi dan Operasi. BPFE. Yogyakarta.

Heize J dan Barry R. 2010. Manejemen Operasi (terjemahan). Salemba Empat. Jakarta.

Karina A, Ismono RH, dan Nugraha A. 2015. Penentuan harga pokok produksi usaha penggemukan sapi: studi kasus usaha penggemukan sapi milik kastamar di Kecamatan Terbanggi Besar Kabupaten Lampung Tengah. Jurnal Ilmu Ilmu Agribisnis, $\quad 3(3)$ : 277-286. https://jurnal.fp.unila.ac.id/index.php/JIA/artic le/view/1052/957. [30 November 2020]

Pertiwi KA, Affandi MI, dan Kasymir E. 2015. Nilai tambah, pengendalian persediaan bahan baku dan pendapatan usaha pada kub bina sejahtera di Kelurahan Kangkung Kecamatan Bumi Waras Kota Bandar Lampung. Jurnal Ilmu Ilmu Agribisnis, 3(1): 26-31. http://jurnal.fp.unila.ac.id/index.php/JIA/articl e/view/1014/919. [1 November 2019].
Setyanto N. 2019. Analisis pengendalian persediaan bahan baku pakan ternak dengan metode eoq (economic order quantity) pada Koperasi SAE Pujon Malang. Jurnal Ilmiah FEB, 8 https://jimfeb.ub.ac.id/index.php/jimfeb/articl e/view/6222. [11 Juli 2020].

Stevenson WJ dan Chee CS. 2014. Manajemen Operasi Perspektif Asiaedisi 9, Buku 2. Salemba Empat. Jakarta.

Wulandari D, Widjaya S, dan Suryani A. 2017. Analisis pengendalian persediaan bahan baku pakan sapi CV Satriya Feed Lampung di Kecamatan Terbanggi Besar Kabupaten Lampung Tengah. Jurnal Ilmu Ilmu Agribisnis, 5(3): 250-257. http://jurnal.fp.unila.ac.id/index.php/JIA/articl e/view/1637/1463. [1 November 2019].

Zubaidah H dan Rizki MSS. 2015. Tinjauan pengawasan persediaan barang dagang pada PT Mitra Tani Sari Panyabungan. Jurnal Bisnis Administrasi, 4(1): 42-52. https://ejurnal.plm.ac.id/index.php/BISA/article/view/137. [7 September 2020] . 